present in a lattice may be constrained by geometrical or other factors, making it possible to overcome the difficulty outlined above. This appears to be the case in many studies of defects in complex oxides. However in the case of dislocations in metals and semiconductors, this difficulty cannot be ignored. At a lower level of resolution, a method has been developed for using weak diffracted beams to study lattice defects \{the weak-beam method [Cockayne, D. J. H., Ray, I. L. F. \& Whelan, M. J. (1969). Phil. Mag. 20, 1265-1270]\}. In this method the diffracted beam acts as a probe, having increased scattering in regions of large lattice distortion. By this means, the ability to locate defect cores and to characterize defect geometries has been improved in resolution by an order of magnitude over previous diffraction contrast techniques. Although with standard high-resolution microscopes the method is limited experimentally to a resolution of approximately $1.5 \mathrm{~nm}$ (because of the low image intensity and long exposure times), there is experimental evidence that developments in high-brightness electron sources will improve the resolution attainable. The method has been applied to a wide range of problems in crystal defect studies, and the limitations on image interpretation have been investigated in some detail. The parameter of incident-beam convergence angle appears to be important in damping the dependence of the image upon defect depth and foil thickness. This is relevant to use of the weak-beam method for obtaining accurate size-density determinations of small point-defect clusters. The possibility of the increased image resolution enabling experimental measurements of the parameters of dislocation core models to be made is being investigated. Initial theoretical and experimental results indicate that this method may provide an experimental means for differentiating between models of defect cores.

\title{
Diffraction Contrast of Small Point-Defect Agglomerates as Studied by Transmission Electron Microscopy (TEM)
}

\author{
BY M. RÜHLE \\ Max-Planck-Institut für Metallforschung, Institut für Werkstoffwissenschaften, Stuttgart, Germany (BRD)
}

(Received 4 June 1974)

Point Defect Agglomerates (PDA) are frequently observed in particle-irradiated or quenched metals. The sizes of the PDA are often so small that their shape cannot be resolved directly with the electron microscope. In the paper methods are outlined by which the shape (cavities, Frank dislocation loop or perfect dislocation loop) and nature (clusters of vacancies or interstitials) can be determined by means of an electron microscopical analysis. The PDA can be subdivided roughly into two groups: PDA with and without strain field in the surrounding crystal matrix, respectively. In the first case the TEM images are determined mainly by the strain field rather than by the (atomistic) structure of the PDA. The identification of such PDA requires in general three steps [Wilkens, M. (1970). Modern Diffraction and imaging Techniques in Materials Science, Edited by S. Amelinckx et al., p. 233. Amsterdam: NorthHolland; Rühle, M. (1969). Radiation Damage in Reactor Materials, Vol. 1, 113. Vienna: IAEA; Wilkens, M. (1974). In Proc. Int. School on Electron Microscopy, Erice, Edited by U. Valdré and E. Ruedl. Luxembourg: C. I. D.]: (i) imaging the PDA under different, well defined diffraction conditions, (ii) calculations of the contrast figures for relevant models of PDA, and (iii) comparison of the observed and calculated contrast figures. For the first time, this concept was applied successfully for PDA in neutronirradiated and ion-bombarded f.c.c. materials [Rühle, M., Wilkens, M. \& Essmann, U. (1965). Phys. Stat. Sol. 11, 819; Rühle, M. \& Wilkens, M. (1967). Phil. Mag. 15, 1075; Rühle, M., Häussermann, F. \& Rapp, M. (1970). Phys. Stat. Sol. 39, 609.], the PDA were revealed as Frank dislocation loops. The experimental observations in b.c.c. and h.c.p. materials suggested that the PDA are perfect dislocation loops. In these cases for the determination of the loop plane and the Burgers vector contrast calculations (step ii) have to be done for a very large number of different loop configurations. Therefore, for particular diffraction conditions specially adopted approximation methods for the calculation of the contrast figures of small PDA were developed [Wilkens, M. \& Rühle, M. (1972). Phys. Stat. Sol. (b) 49, 749]. and applied successfully to PDA in b.c.c. and h.c.p. materials [Häussermann, F., Rühle, M. \& Wilkens, M. (1972). Phys. Stat. Sol. (b) 50, 445; Föll, H. Wilkens, M. (1974). To be published]. Among small defects without strain field (e.g., cavities, incoherent precipitates, disordered zones, etc.) the diffraction contrast of cavities is of special interest. In this case the sign and the size of the contrast depend very sensitively on the focusing conditions of the objective lens [Rühle, M. (1972). Radiation-Induced Voids in Metals, Edited by J. W. Corbett and L. C. Ianniello, p. 255. USAEC; Rühle, M. \& Wilkens, M. (1972). Proc. Sth Europ. Reg. Conf. on Electron Microscopy, Manchester, p. 416; Rühle, M. \& Wilkens, M. (1974). Proc. 8th Int. Congress on Electron Microscopy, Canberra]. This is particularly important for cavities which are very small compared to the thickness of the specimen. By imaging small cavities (in a thin foil) in the defocused mode further information on the internal structure of the cavities can be obtained [Rühle, M. \& Wilkens, M. (1974). Submitted for publication]. 